\title{
ESTABILIDADE OXIDATIVA DE AMÊNDOAS DE NOZ MACADÂMIA SECAS POR MICRO-ONDAS COM AR QUENTE ${ }^{1}$
}

\author{
Flávio Alves da Silva ${ }^{2}$, Lireny Aparecida Guaraldo Gonçalves ${ }^{3}$, Clarissa Damiani², \\ Maria Ássima Bittar Gonçalves ${ }^{2}$, Manoel Soares Soares Júnior ${ }^{2}$, Antonio Marsaioli Júnior ${ }^{4}$
}

\begin{abstract}
OXIDATIVE STABILITY OF MACADAMIA

NUTS DRYED WITH HOT AIR MICROWAVES

The macadamia tree (Macadamia integrifolia Maiden \& Betche) produces a nut of highly commercial value, distinguishable from other nuts by its delicate flavour and oil quality. This study aimed to compare the oxidative stability of dried nuts, with the application of hot air microwave energy, in relation to conventional drying. The analyses were performed at the beginning stage (time zero), at 90 days, and 180 days of storage, to evaluate the percentage of free fatty acids, peroxide values, induction period, fatty acid composition, and tocopherol/ tocotrienol content. The percentage of free fatty acids varied from 0.095 (MW1) to 0.124 (MW3) and from 0.123 to 0.148 (CVL); peroxide values (meq $\mathrm{O}_{2} \mathrm{~kg}^{-1}$ oil) ranged from 0.77 (MW2) to 2.57 (MW1) and from 1.52 to 3.29 (CVL); the induction period (h) from 16.7 (MW2) to 13.6 (MW4) and from 11.9 to

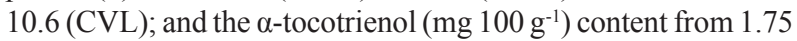
to 2.19 (MW1) and from 2.14 to 2.19 (CVL), for microwave and conventional drying, respectively. The fatty acid composition values did not change during storage, in relation to the drying processes applied. The microwaves drying method was more efficient, regarding the macadamia nuts oxidative stability, when compared to the conventional drying method.
\end{abstract}

KEY-WORDS: Macadamia integrifolia Maiden \& Betche; microwave; drying.

\section{INTRODUÇÃO}

Anogueira macadâmia (Macadamia integrifolia Maiden \& Betche) é uma árvore da família Proteaceae, originária das florestas tropicais da Austrália, cuja noz é considerada a mais saborosa, dentre as demais comercializadas no mundo (Dierberger \& Marino Netto 1985). Toledo Piza (1991) descreve que o fruto da

\section{RESUMO}

A nogueira macadâmia (Macadamia integrifolia Maiden \& Betche) produz amêndoas de alto valor comercial, que se destacam pelo fino sabor e qualidade de seu óleo. $\mathrm{O}$ objetivo deste trabalho foi estudar a estabilidade oxidativa de amêndoas secas, com aplicação de energia de micro-ondas com ar quente, em comparação ao processo de secagem convencional. As análises, realizadas no início (tempo zero), com 90 dias e 180 dias de armazenamento, avaliaram ácidos graxos livres, índice de peróxido, período de indução, composição em ácidos graxos e teor de tocoferol/tocotrienol. O teor de ácidos graxos livres (\%) das amêndoas de noz macadâmia variou de 0,095 (MW1) a 0,124 (MW3) e de 0,123 a 0,148 (CVL); os índices de peróxidos (meq $\mathrm{O}_{2} \mathrm{~kg}^{-1}$ de óleo) entre 0,77 (MW2) e 2,57 (MW1) e de 1,52 a 3,29 (CVL); o período de indução (h) de 16,7 (MW2) a 13,6 (MW4) e entre 11,9 e 10,6 (CVL); o teor de $\alpha$-Tocotrienol (mg $100 \mathrm{~g}^{-1}$ ) de 1,75 a 2,19 (MW1) e de 2,14 a 2,19 (CVL), respectivamente, para a secagem com micro-ondas e convencional. Os valores da composição em ácidos graxos não se alteraram durante o armazenamento, com os processos de secagem utilizados. O método de secagem com micro-ondas mostrou-se mais eficiente, em relação à estabilidade oxidativa das amêndoas de noz macadâmia, quando comparado ao processo de secagem convencional.

PALAVRAS-CHAVES: Macadâmia integrifolia Maiden \& Betche; micro-ondas; secagem.

macadâmia possui pericarpo de consistência carnosa e cor verde, usualmente chamado de carpelo. Envolvida pelo carpelo, encontra-se a noz em casca, cuja concha apresenta coloração marrom brilhante e, no interior, está a amêndoa de cor creme. As amêndoas são consumidas desidratadas ou torradas e são utilizadas na fabricação de cosméticos e em confeitaria, sendo fonte de óleo com qualidade comparável à do azeite de oliva.

1. Trabalho recebido em maio/2010 e aceito para publicação em jun./2011 (nº registro: PAT 9961/ DOI: 10.5216/pat.v41i2.9961).

2. Universidade Federal de Goiás, Escola de Agronomia e Engenharia de Alimentos, Goiânia, GO, Brasil.

E-mails: flaviocamp@gmail.com,damianiclarissa@hotmail.com, assima.bittar@gmail.com,mssoaresjr@hotmail.com.

3. Universidade Estadual de Campinas, Faculdade de Engenharia de Alimentos, Departamento de Tecnologia de Alimentos, Campinas, SP, Brasil.E-mail: lireny@fea.unicamp.br.

4. Instituto de Tecnologia de Alimentos, Campinas, SP, Brasil.E-mail: tonymars@uol.com.br. 
A amêndoa da noz macadâmia é rica em óleos monoinsaturados (ácidos graxos oléico e palmitoléico), disputados pela indústria de cosméticos, para formulação de hidratantes, e por laboratórios farmacêuticos, devido à sua propriedade de redução dos níveis de colesterol, em seres humanos. O óleo pode, ainda, ser utilizado para cozinhar ou temperar saladas (Kaijser et al. 2000).

Como todas as nozes, a macadâmia contém elevada quantidade de óleo. Mason \& Wills (2000) relataram quantidade de óleo variando entre $66,3 \% \mathrm{e}$ $81,2 \%$ e umidade entre $1 \%$ e $1,5 \%$ (b.s.), de acordo com a cultivar, condições edafoclimáticas e práticas de cultivo. Os ácidos graxos de maior ocorrência no óleo de nozes de macadâmia são: oléico (40$65 \%$ ), palmitoléico (15-30\%), palmítico (7-24\%), esteárico (2-5\%), linoléico (1,4-4,5\%), araquídico (1,2-4,5\%) e mirístico (0,6-1,8\%) (Cavaletto 1983, Dierberger \& Marino Netto 1985, Duke 1989, Mason \& McConachie 1994, Kaijser et al. 2000).

Existe intensa procura, tanto por consumidores como por indústrias de alimentos, por óleos e gorduras de alta estabilidade, que permitam prolongar a vida-de-prateleira dos seus produtos. Inúmeros fatores determinam a estabilidade de óleos e gorduras, destacando-se a composição química e as condições de processamento. Quando se menciona a estabilidade de óleos e gorduras, refere-se ao comportamento futuro do produto, com respeito às suas características de qualidade. Este comportamento depende, além da história do material, da composição deste, pois a presença de compostos antioxidantes ou pró-oxidantes e o conteúdo de ácidos graxos insaturados, dentre outros, determinam sua estabilidade oxidativa (Barrera-Arellano 1998, Moretto \& Fett 1998).

A qualidade de óleos e gorduras, ou de materiais que os contêm, sempre está relacionada com o fenômeno da rancidez, que é, sem dúvida, o fator de deterioração mais importante, neste tipo de produto. Rancidez é definida como alteração de óleos e gorduras organolepticamente detectável, que, dentre outras consequências, ocasiona deterioração de sabor e odor, deprecia o produto e reduz seu valor nutricional (Barrera-Arellano 1993).

As micro-ondas são fonte ímpar de energia, porque geram calor dentro dos materiais processados, resultando em tempos de processamento mais curtos, maior rendimento de produto final e, usualmente, qualidade superior à obtida com técnicas convencionais de processamento (Decareau \& Peterson 1986).
Silva \& Marsaioli Júnior (2004) testaram o uso de energia de micro-ondas, combinada com ar quente, na secagem de amêndoas de castanha-do-Brasil e os tempos de secagens obtidos foram bem menores, em relação ao tempo gasto na secagem convencional (10 horas para a secagem com micro-ondas e 72 horas para a secagem convencional), mantendo-se a preservação do produto final por até seis meses. Assim, o objetivo deste trabalho foi avaliar a estabilidade, durante 180 dias de armazenamento, de amêndoas de noz macadâmia seca, após aplicação de energia de micro-ondas com ar quente, e compará-la com a de amêndoas secas pelo processo convencional (secagem convectiva).

\section{MATERIAL E MÉTODOS}

Os experimentos foram realizados nos laboratórios de micro-ondas e óleos e gorduras da Faculdade de Engenharia de Alimentos da Universidade Estadual de Campinas, em 2005.

Utilizaram-se, no experimento de secagem e armazenamento, frutos descarpelados da nogueira macadâmia (Macadamia integrifolia Maiden \& Betche), com umidade média em torno de $10 \%$ em base seca (b.s.), fornecidos pela Queen Nut Macadâmia, sediada em Dois Córregos (SP), que, também, doou amêndoas secas em sistema convencional, com umidade em torno de $1,5 \%$ (b.s.). Ambas as amostras pertenciam ao mesmo lote de produção.

Foram utilizados, para a determinação da umidade da amêndoa de noz macadâmia, $2 \mathrm{~g}$ de amostra, colocados dentro de uma estufa a vácuo (FANEM modelo 099EV), durante 5 horas, a $95-100^{\circ} \mathrm{C}$, sob pressão inferior a $100 \mathrm{~mm} \mathrm{Hg}(13,3 \mathrm{kPa})$, até a obtenção de massa constante (AOAC 1997).

Os ensaios foram realizados em forno de micro-ondas adaptado (Figura 1) (Silva et al. 2006). Quatro tratamentos de secagem foram realizados em micro-ondas com ar quente, utilizando-se delineamento inteiramente casualizado (DIC), com 3 repetições. As amêndoas secas com aplicação de micro-ondas com ar quente foram codificadas como MW1 $\left(58^{\circ} \mathrm{C}, 64^{\circ} \mathrm{C}\right), \operatorname{MW} 2\left(62^{\circ} \mathrm{C}, 64^{\circ} \mathrm{C}\right)$, MW3 $\left(58^{\circ} \mathrm{C}\right.$, $\left.68^{\circ} \mathrm{C}\right)$ e MW4 $\left(62^{\circ} \mathrm{C}, 68^{\circ} \mathrm{C}\right.$ ) (os valores entre parênteses se referem à temperatura do ar e à temperatura de ajuste, respectivamente). Uma amostra de amêndoa de noz macadâmia, seca convencionalmente (código CVL), foi utilizada para a comparação com as secas por micro-ondas com ar quente. Foi avaliada a influ- 


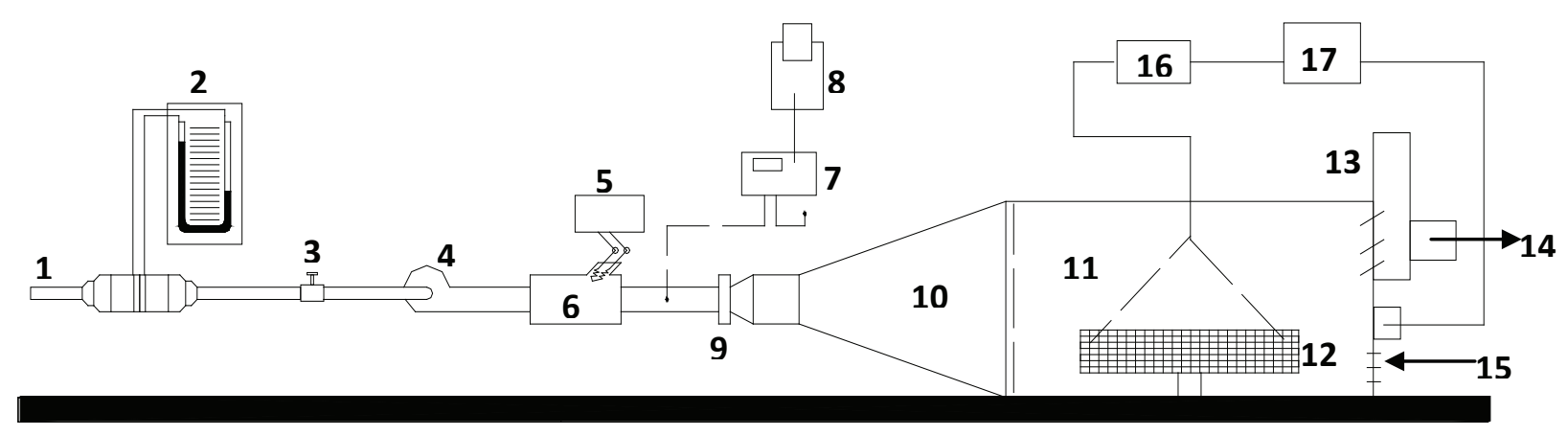

Figura 1. Adaptação de forno de micro-ondas doméstico: (1) entrada de ar, (2) manômetro, (3) válvula, (4) ventilador, (5) controlador de temperatura, (6) aquecedor elétrico, (7) indicador de temperatura, (8) registrador de temperatura, (9) conector rápido, (10) difusor de ar, (11) cavidade de micro-ondas, (12) cesto de produto, (13) janela de exaustão, (14) saída de ar, (15) ar de resfriamento do gerador de micro-ondas, (16) sensoriamento infravermelho e (17) temperatura de set point do controlador para chavear o sistema liga/desliga do magnetron.

ência das variáveis temperatura do ar e temperatura de ajuste (sistema de controle de temperatura do produto, em função da potência aplicada, ou seja, temperatura de set point do controlador, para chavear o sistema liga/desliga do magnetron) sobre a estabilidade oxidativa das amêndoas (índice de peróxido, percentagem de ácidos graxos livres e período de indução). Uma amostra controle foi codificada com a letra $\mathrm{C}$, permanecendo in natura e armazenada a $-18^{\circ} \mathrm{C}$, durante todo o tempo de armazenamento.

A massa inicial das amostras foi fixada em $0,9 \mathrm{~kg}$, a potência de micro-ondas utilizada nos ensaios de $300 \mathrm{~W}$ (densidade de potência de $0,349 \mathrm{~W} \mathrm{~g}^{-1}$ ) e a vazão do ar de entrada e a velocidade do ar foram fixadas em $2,8 \mathrm{~m}^{3} \mathrm{~min}^{-1} \mathrm{e} 1,0 \mathrm{~m} \mathrm{~s}^{-1}$, respectivamente. Os processos de secagem foram conduzidos até a umidade das nozes em casca atingirem valor próximo a 3,7\% (b.s.), ou seja, até as amêndoas alcançarem umidade em torno de $1,5 \%$ (b.s.). O tempo de secagem variou de $270 \mathrm{~min}$. a $330 \mathrm{~min}$. e a umidade relativa do ar, no período de realização dos experimentos, entre $56 \%$ e $60 \%$.

Após a secagem da noz macadâmia em casca, as amêndoas foram extraídas mecanicamente, embaladas a vácuo, em filmes laminados compostos de camadas de polietileno de baixa densidade (PEBD/ NYLON/PEBD), e armazenadas durante seis meses, sob temperatura ambiente (média de $25^{\circ} \mathrm{C}$ ) e umidade relativa média de $50 \%$. As amêndoas secas convencionalmente foram embaladas e armazenadas da mesma forma. Foram realizadas avaliações da qualidade das amostras no tempo inicial (tempo zero), com 90 dias e 180 dias de armazenamento.
O óleo extraído para análise do índice de peróxido da amêndoa foi obtido através de extração mecânica a frio, utilizando-se uma prensa hidráulica manual (Charlott Prensas Hidráulicas LTDA), com 60 toneladas de força. O índice de peróxido do óleo das amostras foi determinado por titulometria, usando-se o método Cd 8b-90 (AOCS 2002).

O período de indução, baseado na determinação da condutividade elétrica dos produtos voláteis da degradação, foi determinado pelo método $\mathrm{Cd}$ 12b-92 (AOCS 2002), utilizando-se temperatura de $120^{\circ} \mathrm{C}$ e fluxo de ar de $10 \mathrm{~L} \mathrm{~h}^{-1}$. O percentual de ácidos graxos livres foi avaliado por titulometria, pelo método Ca 5a-40 (AOCS 2002). A composição em ácidos graxos foi determinada pelo método Ce 1f-96 (AOCS 2002). Para isto, procedeu-se à extração dos ésteres metílicos, por esterificação, utilizando-se o método Ce 2-66 (AOCS 2002). Os ésteres metílicos dos ácidos graxos das amostras foram submetidos a análise de cromatografia em fase gasosa, utilizando-se um cromatógrafo gasoso, marca CGC AGILENT 6850 SERIES GC SYSTEM, com coluna capilar de sílica fundida (DB-23 Agilent; 50\% cianopropilmetilpolissiloxano; $60 \mathrm{~m}$ de comprimento; $0,25 \mathrm{~mm}$ de diâmetro interno; $0,25 \mu \mathrm{m}$ de espessura do filme), equipado com detector de ionização de chama. As condições de operação do cromatógrafo foram: temperatura do detector de $280^{\circ} \mathrm{C}$; temperatura do injetor de $250^{\circ} \mathrm{C}$; temperatura do forno de $110^{\circ} \mathrm{C}$, por $5 \mathrm{~min}$., $110-215^{\circ} \mathrm{C}\left(5^{\circ} \mathrm{C}\right.$ por min.) e $215^{\circ} \mathrm{C}$ (durante $24 \mathrm{~min}$.); gás de arraste: hélio; e volume injetado de $1,0 \mu \mathrm{L}$.

Para determinação dos tocoferóis e tocotrienóis, utilizou-se o método Ce8-89 (AOCS 2002). 
Fez-se uso da cromatografia líquida de alta eficiência (CLAE), utilizando-se o cromatógrafo líquido de Perkin Elmer 250, com detector de fluorescência Shimadzu; excitação de 290 nm; emissão de 330 nm; coluna Merck 250 x 4 mm Li Chrosorb Si $60(5 \mu \mathrm{m})$; fase móvel hexano/isopropanol (98/2); e fluxo 1,0 $\mathrm{mL} / \mathrm{min}$.

Análises de estabilidade, como índice de peróxido, teor de ácidos graxos livres e período de indução, foram realizadas em triplicata. Caracterizaram-se, também, o óleo extraído das amêndoas, com relação à sua composição em ácidos graxos, e o teor de tocoferol/tocotrienol, no tempo zero e no final do armazenamento (180 dias). Os dados obtidos foram submetidos a análise de variância (ANOVA) e as médias comparadas pelo teste Tukey, a 5\%, com o auxílio do programa STATISTICA 5.0.

\section{RESULTADOS E DISCUSSÃO}

Avaliando-se o tempo de armazenamento, em cada tratamento, para os ácidos graxos livres, verificou-se que não houve diferença significativa $(\mathrm{p} \leq 0,05)$, durante os 180 dias de armazenamento, com teor médio de ácidos graxos livres de $0,106 \%$, no tratamento MW1; $0,110 \%$, no MW2; $0,110 \%$, no MW3; $0,105 \%$, no MW4; e $0,136 \%$, no CVL. O mesmo foi observado quando se avaliou o tratamento dentro de cada tempo, ou seja, verificou-se que, do tempo 0 até os 180 dias subsequentes, não houve diferenças significativas $(p \leq 0,05)$ entre os tratamentos, com média de $0,101 \%$, no início do experimento; $0,111 \%$, após 90 dias; e $0,123 \%$, ao final dos 180 dias (Tabela 1).

O baixo valor de acidez (Tabela 1) apresentada na fração lipídica da amêndoa de noz macadâmia, durante todo o período de armazenamento, indica que não ocorreram reações hidrolíticas no produto. A inativação de enzimas que, geralmente, estão envolvidas no processo hidrolítico, durante o processamento (secagem) das amêndoas de noz macadâmia, provavelmente, deve ser o fator responsável por este comportamento. Observou-se, também, que os valores de \% AGL ficaram abaixo do limite máximo tolerado para óleos brutos, preconizado pela legislação brasileira (Brasil 1999), que é de 1,5\% AGL. A amostra controle (C), que permaneceu in natura $\mathrm{e}$ armazenada a $-18^{\circ} \mathrm{C}$, durante todo o tempo de armazenamento, teve o teor de ácidos graxos livres variando 0,054-0,055\%, no período. Souza et al. (2007), que avaliaram a estabilidade de óleo de macadâmia de variedades brasileiras, também encontraram baixos valores para $\% \mathrm{AGL}$, o que realmente indica o quanto a amêndoa de noz macadâmia é estável, no que diz respeito à oxidação.

Tabela 1. Ácidos graxos livres (AGL), índice de peróxido (IP) e período de indução (PI) presentes na fração lipídica de amêndoas de noz macadâmia, em três tempos de armazenamento, após a secagem com aplicação de energia de micro-ondas com ar quente (Campinas, SP, 2005).

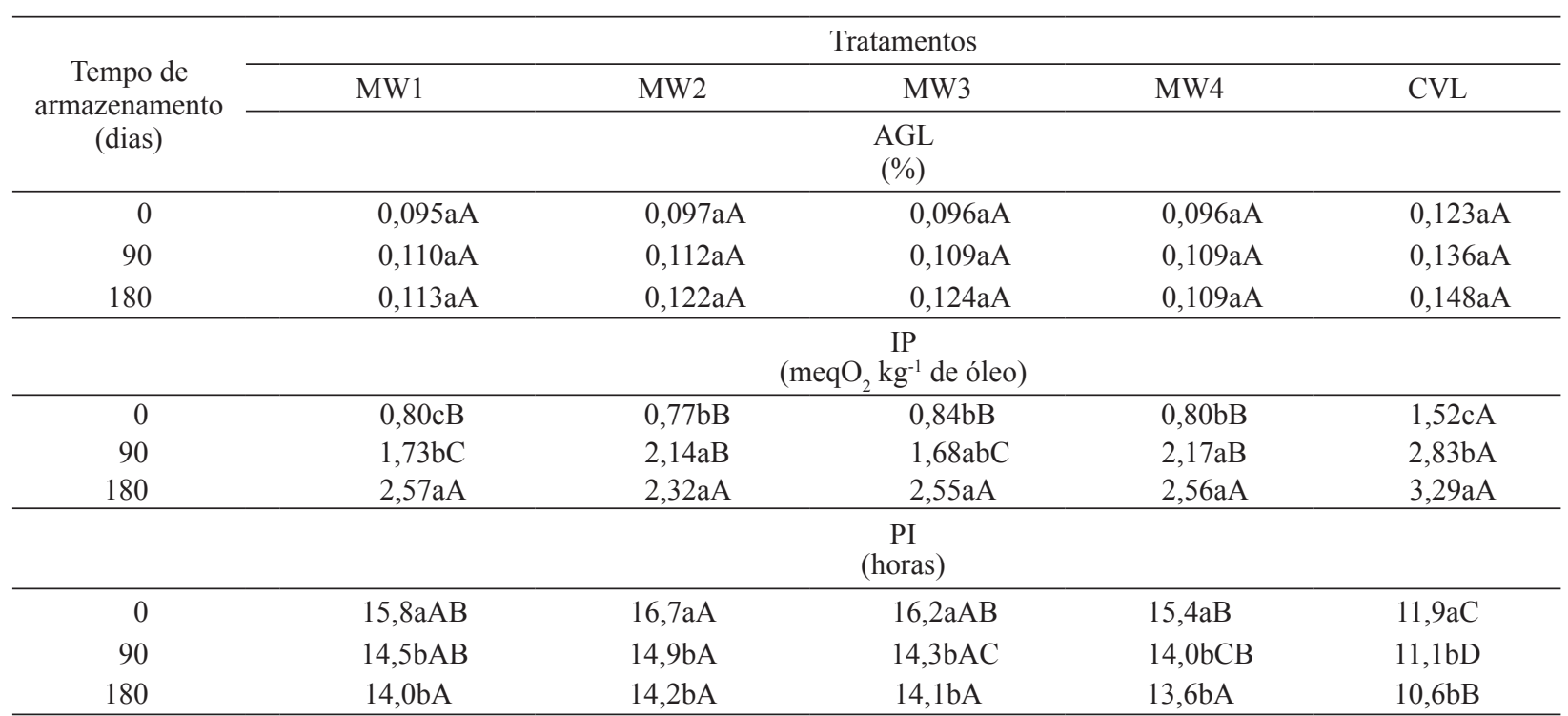

Médias com a mesma letra minúscula (colunas) e maiúscula (linhas) não são significativamente diferentes, pelo teste Tukey (p $\leq 0,05)$.

Tratamentos (temperatura do ar/temperatura de ajuste): MW1 $\left(58^{\circ} \mathrm{C}, 64^{\circ} \mathrm{C}\right), \mathrm{MW} 2\left(62^{\circ} \mathrm{C}, 64^{\circ} \mathrm{C}\right), \mathrm{MW} 3\left(58^{\circ} \mathrm{C}, 68^{\circ} \mathrm{C}\right)$ e $\mathrm{MW} 4\left(62^{\circ} \mathrm{C}, 68^{\circ} \mathrm{C}\right)$. 
Para o índice de peróxido (Tabela 1), ao se analisar o tempo de armazenamento, em cada tratamento, verificou-se que o MW1 e o CVL obtiveram IPs diferentes $(\mathrm{p} \leq 0,05)$, no decorrer dos 180 dias de armazenamento, com incremento de 0,8 meq $\mathrm{O}_{2} \mathrm{~kg}^{-1}$ para 2,57 meq $\mathrm{O}_{2} \mathrm{~kg}^{-1}$ de óleo, no MW1, e de 1,52 meq $\mathrm{O}_{2} \mathrm{~kg}^{-1}$ para 3,29 meq $\mathrm{O}_{2} \mathrm{~kg}^{-1}$, no CVL. Os tratamentos MW2 e MW4, aos 90 dias de armazenamento, diferiram, em relação ao tempo zero, com média de 0,77 meq $\mathrm{O}_{2} \mathrm{~kg}^{-1}$, 0,80 meq $\mathrm{O}_{2} \mathrm{~kg}^{-1}$ e 0,80 meq $\mathrm{O}_{2} \mathrm{~kg}^{-1}$ de óleo, respectivamente; e 2,26 meq $\mathrm{O}_{2} \mathrm{~kg}^{-1}, 0,80$ meq $\mathrm{O}_{2} \mathrm{~kg}^{-1} \mathrm{e}$ 2,27 meq $\mathrm{O}_{2} \mathrm{~kg}^{-1}$ de óleo, respectivamente, após os 90 dias. Já o tratamento MW3 apresentou diferença apenas no início do tratamento $\left(0,84\right.$ meq $\mathrm{O}_{2} \mathrm{~kg}^{-1}$ de óleo $)$ e no final (2,55 meq $\mathrm{O}_{2} \mathrm{~kg}^{-1} \mathrm{de}$ óleo). Sousa et al. (2007) também encontraram baixos valores de IP (máximo de 0,64 meq $\mathrm{O} 2 \mathrm{~kg}^{-1}$ ), na fração lipídica de amêndoas de noz macadâmia crua e salgada, armazenadas por 5 meses e embaladas a vácuo, em saco de alumínio multicamadas.

Avaliando-se o IP, em relação ao tratamento, no início do experimento, apenas o tratamento CVL teve IP diferente dos outros tratamentos $(\mathrm{p} \leq 0,05)$, com média de 1,52 meq $\mathrm{O}_{2} \mathrm{~kg}^{-1}$ de óleo. Aos 90 dias, os IPs do MW1 e MW3 foram iguais ( $p>0,05)$, com média de 1,73 meq $\mathrm{O}_{2} \mathrm{~kg}^{-1}, 0,80$ meq $\mathrm{O}_{2} \mathrm{~kg}^{-1}$ e 1,68 meq $\mathrm{O}_{2} \mathrm{~kg}^{-1}$ de óleo, respectivamente, assim como os tratamentos MW2 e MW4, os quais obtiveram médias de 2,14 meq $\mathrm{O}_{2} \mathrm{~kg}^{-1}, 0,80$ meq $\mathrm{O}_{2} \mathrm{~kg}^{-1} \mathrm{e}$ 2,17 meq $\mathrm{O}_{2} \mathrm{~kg}^{-1}$ de óleo $(\mathrm{p}>0,05)$, respectivamente. O tratamento CVL diferiu $(\mathrm{p} \leq 0,05)$ dos demais, com média de 2,83 meq $\mathrm{O}_{2} \mathrm{~kg}^{-1}$ de óleo. Aos 180 dias, os tratamentos não diferiram entre si $(p>0,05)$.

A amostra seca convencionalmente (CVL) apresentou o maior valor de IP, desde o início até o final do período de armazenamento, indicando que o processo de secagem com aplicação de micro-ondas e ar quente agrava menos as reações oxidativas da amêndoa e isto se deve, principalmente, ao fato de que, neste processo, o tempo de secagem é bem menor, quando comparado aos tempos de secagem obtidos pelo processo convencional, ou seja, o produto fica menos tempo exposto a temperaturas elevadas.

Nota-se que, apesar do aumento destes valores, os índices de peróxido obtidos não alcançaram o limite máximo tolerado para óleos brutos estipulado pela legislação brasileira (Brasil 1999), que é de 10 meq $\mathrm{O}_{2} \mathrm{~kg}^{-1}$. O aumento deste índice, durante o armazenamento, é indicativo de que se iniciaram as reações oxidativas. A amostra controle (C) apresentou valores variando $0,54-0,55$ meq $\mathrm{O}_{2} \mathrm{~kg}^{-1}$ de óleo, durante todo o armazenamento. Souza et al. (2007), encontraram, também, baixos IPs, mesmo para amêndoas submetidas ao processo de fritura (máximo de 2,75 meq $\mathrm{O}_{2} \mathrm{~kg}^{-1}$ ).

No processo de deterioração oxidativa, há um período inicial, denominado período de indução (PI), no qual a velocidade de reação é baixa, e, quanto maior o período de indução, mais estável é o óleo. Com o tempo de armazenamento, o período de indução tende a decrescer (Rauen-Miguel et al. 1992). Avaliando-se a influência do tempo de armazenamento, em cada tratamento, sobre o PI, verificou-se que a primeira diferença $(\mathrm{p} \leq 0,05)$ ocorreu ao final dos 90 dias de armazenamento, para todos os tratamentos, mantendo-se igual até o final do armazenamento (Tabela 1). Na análise dos tratamentos, observou-se, no início do armazenamento, que os tratamentos MW1, MW2 e MW3 foram iguais ( $p>0,05)$, diferindo $(\mathrm{p} \leq 0,05)$ dos tratamentos MW4 e CVL, que também diferiram $(\mathrm{p} \leq 0,05)$ entre si. Aos 90 dias, MW1, MW2 e MW3 foram iguais ( $p>0,05)$, diferindo do CVL. Os tratamentos MW2 e CVL foram diferentes $(\mathrm{p} \leq 0,05)$, com média de $14,9 \mathrm{~h}$ e $11,1 \mathrm{~h}$, respectivamente. Aos 180 dias de armazenamento, somente o tratamento CVL apresentou PI diferente $(p \leq 0,05)$, enquanto os demais tratamentos não diferiram entre si $(p>0,05)$. Sousa et al. (2007) também encontraram altos valores de PI (máximo de 24,3 h), na fração lipídica de amêndoas de noz macadâmia crua e salgada, armazenadas por 5 meses e embaladas a vácuo, em saco de alumínio multicamadas.

Comparando-se os valores de PI com os do IP, observa-se que os tratamentos que tiveram os maiores valores de índice de peróxido foram os que apresentaram o menor período de indução. Nota-se, também, que os menores valores de período de indução obtidos foram os da amostra seca convencionalmente (CVL), evidenciando que o processo convencional de secagem afeta negativamente, com maior intensidade, a vida-de-prateleira da amêndoa de noz macadâmia, se comparado ao método de secagem por micro-ondas com ar quente. Para a amostra controle $(\mathrm{C})$, os valores do PI variaram 18,9-19,5 (h), durante todo o período de armazenamento, mantendo-se, praticamente, constantes.

Pode-se verificar que a composição em ácidos graxos não se alterou $(\mathrm{p}>0,05)$, durante o armazenamento (Tabela 2). Este fato é uma evidência de que as reações oxidativas foram pequenas, durante o armazenamento, já que estados oxidativos avançados levam à redução de ácidos graxos insaturados, 
Tabela 2. Composição em ácidos graxos das frações lipídicas de amêndoas de noz macadâmia (M. integrifolia), secas com aplicação de energia de micro-ondas com ar quente (Campinas, SP, 2005).

\begin{tabular}{lrrrrrrrr}
\hline \multicolumn{1}{c}{ Ácidos graxos (\%) } & \multicolumn{4}{c}{0 dias } & \multicolumn{4}{c}{180 dias } \\
\cline { 2 - 8 } & MW1 & MW4 & CVL & *C & MW1 & MW4 & CVL & $*$ C \\
\hline C14:0 (ácido mirístico) & 0,77 & 0,80 & 0,80 & 0,78 & 0,72 & 0,81 & 0,81 & 0,78 \\
C16:0 (ácido palmítico) & 7,32 & 7,69 & 7,55 & 7,60 & 7,62 & 7,47 & 7,45 & 7,62 \\
C16:1 (ácido palmitoléico) & 15,72 & 15,76 & 15,47 & 14,54 & 15,14 & 14,95 & 15,33 & 14,54 \\
C18:0 (ácido esteárico) & 4,32 & 3,91 & 4,07 & 3,90 & 3,99 & 4,12 & 4,09 & 3,90 \\
C18:1 (ácido oléico) & 63,31 & 63,55 & 63,62 & 64,59 & 63,81 & 64,14 & 63,78 & 64,62 \\
C18:2 (ácido linoléico) & 1,37 & 1,40 & 1,42 & 1,52 & 1,51 & 1,40 & 1,40 & 1,52 \\
C18:3 (ácido linolênico) & 0,13 & 0,12 & 0,12 & 0,11 & 0,12 & 0,11 & 0,12 & 0,12 \\
C20:0 (ácido araquídico) & 3,13 & 2,89 & 2,99 & 2,90 & 3,00 & 3,00 & 3,00 & 2,89 \\
C20:1 (ácido eicosenóico) & 2,48 & 2,45 & 2,50 & 2,62 & 2,64 & 2,59 & 2,58 & 2,58 \\
C22:0 (ácido behênico) & 0,83 & 0,84 & 0,84 & 0,83 & 0,83 & 0,82 & 0,84 & 0,83 \\
C22:1 (ácido erúcico) & 0,27 & 0,27 & 0,27 & 0,28 & 0,28 & 0,27 & 0,28 & 0,28 \\
C24:0 (ácido lignocérico) & 0,33 & 0,33 & 0,33 & 0,33 & 0,33 & 0,33 & 0,33 & 0,33 \\
\% ácidos graxos insaturados & 83,29 & 83,56 & 83,41 & 83,66 & 83,50 & 83,46 & 83,48 & 83,65 \\
\% ácidos graxos saturados & 16,71 & 16,44 & 16,59 & 16,35 & 16,50 & 16,54 & 16,52 & 16,35 \\
\hline
\end{tabular}

* Código da amostra controle, sendo que esta permaneceu in natura e foi armazenada a $-18^{\circ} \mathrm{C}$, durante o tempo de armazenamento.

segundo Kaijser et al. (2000). Dentre os ácidos graxos insaturados encontrados no óleo da amêndoa de noz macadâmia, o ácido graxo oléico foi o mais predominante, com média de $63,93 \%$, seguido do ácido graxo palmitoléico $(15,18 \%)$. Com relação aos ácidos graxos saturados, observou-se que os predominantes foram o ácido palmítico, com média de $7,54 \%$, seguido pelo ácido esteárico (4,04\%). No geral, os ácidos graxos insaturados obtiveram média de $83,5 \%$ e os ácidos graxos saturados média de $16,5 \%$. Os valores encontrados em ácidos graxos estão de acordo com aqueles observados por Cavaletto (1983), Dierberger \& Marino Netto (1985), Duke (1989), Mason \& MccConachie (1994), Kaijser et al. (2000), Sousza et al. (2007) e Freitas \& Naves (2010).

Nas análises dos teores de tocoferol/tocotrienol, realizadas na fração lipídica das amêndoas de noz macadâmia dos ensaios MW1, MW4, CVL e controle (C), verificou-se que apenas o $\alpha$-Tocotrienol foi detectado, apresentando, respectivamente, os

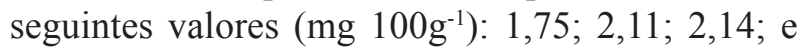
2,36 , no tempo inicial de armazenamento (0 dias), e 2,$19 ; 2,06 ; 2,19$; e 2,35, aos 180 dias. Os outros tocoferóis $(\gamma$-tocotrienol, $\delta$-tocotrienol, $\alpha$-tocoferol e $\gamma$-tocoferol) foram encontrados somente na forma de traços. Este resultado está de acordo com o estudo realizado por Kaijser et al. (2000), os quais também observaram uma maior quantidade de $\alpha$-Tocotrienol, em frações lipídicas de amêndoas de noz macadâmia.

Nota-se que, nas amostras analisadas, os teores de $\alpha$-Tocotrienol não se alteraram ( $p>0,05)$, durante o período de armazenamento da amêndoa. Deve-se salientar, ainda, que os tocoferóis são antioxidantes naturais e que a sua estabilidade está, normalmente, associada ao não desenvolvimento de oxidação, como observado por Pershern et al. (1995), para avelãs, e por Quinn \& Tang (1996) e Kaijser et al. (2000), para noz macadâmia. Esta afirmação é coerente com os baixos valores de índice de peróxidos obtidos neste trabalho.

\section{CONCLUSÃO}

É possível utilizar a secagem de noz macadâmia por micro-ondas, do ponto de vista da estabilidade oxidativa. A secagem com energia de micro-ondas provoca menor impacto, quanto à rancificação, proporcionando o desenvolvimento de características de rancidez menos expressivas, após o processo de secagem e após seis meses de armazenamento, mesmo utilizando-se temperaturas um pouco maiores do que as utilizadas no processo convencional de secagem. Portanto, o método de secagem com micro-ondas é mais eficiente, no que diz respeito à preservação da qualidade natural das nozes de macadâmia, em comparação ao processo de secagem convencional.

\section{REFERÊNCIAS}

AMERICAN OIL CHEMISTS' SOCIETY (AOCS). Official methods and recommended practices of the American Oil Chemist's Society. Champaign: AOCS, 2002. 
ASSOCIATION OF OFFICIAL ANALYTICAL CHEMISTS (AOAC). Official methods of analysis of the Association of Official Analytical Chemists. Gaithersburg: AOAC, 1997.

BARRERA-ARELLANO, D. Estabilidade em óleos e gorduras. Óleos \& Grãos, São Bernado do Campo, n. 13, p. 10-13, 1993.

BARRERA-ARELLANO, D. Estabilidad y utilización de nitrógeno en aceites y grasas. Grasas y Aceites, Sevilla, v. 49, n. 1, p. 55-63, 1998.

BRASIL. Ministério da Saúde. Resolução no 482, de 23 de setembro de 1999 - ANVS. Regulamento técnico para fixação de identidade e qualidade de óleos e gorduras vegetais. Diário Oficial da União, Poder Executivo, Brasília, DF, v. 196. Seção I, p. 82-87.

CAVALETTO, C. G. Macadamia Nut. In: CHAN, H. J. (Ed.). Handbook of tropical foods. New York: Marcel Dekker, 1983. p. 361-397.

DECAREAU, R. V.; PETERSON, R. A. Microwave processing and engineering. Chichester: Ellis Horwood, 1986.

DiERBERGER, J. E.; MARINO NETTO, L. Noz macadamia: uma nova opção para a fruticultura brasileira. São Paulo: Nobel, 1985.

DUKE, J. A. Handbook of nuts. New York: CRC Press, 1989.

FREITAS, J. B.; NAVES, M. M. V. Composição química de nozes e sementes comestíveis e sua relação com a nutrição e saúde. Revista de Nutrição, Campinas, v. 23, n. 2, p. 269-279, 2010.

KAIJSER, A.; DUTTA, P.; SAVAGE, G. Oxidative stability and lipid composition of macadamia nuts grown in New Zealand. Food Chemistry, London, v. 71, n. 1, p. $67-70,2000$.

MASON, R. L.; McCONACHIE, I. A hard met to crak: a review of the Australian macadamia nut industry. Food Australia, Sidney, v. 46, n. 10, p. 466-471, 1994.
MASON, R. L.; WILLS, R. B. H. Macadamia nut quality research: the processing challenge. Food Australia, Sidney, v. 52, n. 9, p. 416-419, 2000.

MORETTO, E.; FETT, R. Tecnologia de óleos e gorduras vegetais na indústria de alimentos. São Paulo: Varela, 1998.

PERSHERN, A. S.; BREENE, W. M.; LULAI, E. C. Analysis of factors influencing lipid oxidation in hazelnuts (corylus spp.). Journal of Food Processing and Preservation, Connecticut, v. 19, n. 1, p. 9-26, 1995.

QUINN, L. A.; TANG, H. H. Antioxidant properties of phenolic compounds in macadamia nuts. Journal of the American Oil Chemists' Society, Berlin, v. 73, n. 11, p. 1585-1588, 1996.

RAUEN-MIGUEL, A. M. O.; ESTEVES, W.; BARRELAARELLAMO, D. Determinación del período de inducción de aceite de soja: correlación entre el Rancimat y otros índices. Grasas y Aceites, Sevilha, v. 43, n. 3, p. 119-122, 1992.

SILVA, F. A. et al. Microwave assisted drying of macadamia nuts. Journal of Food Engineering, London, v. 77 , n. 3, p. 550-558, 2006.

SILVA, F. A.; MARSAIOLI JÚNIOR, A. Estudo comparativo da conservação de castanha-do-Brasil (Bertholletia excelsa) seca por micro-ondas e convencionalmente. Boletim CEPPA, Curitiba, v. 22, n. 2, p. 387-404, 2004.

SOUZA, D. F. S. et al. Estabilidade oxidativa dos óleos de macadâmia e de pistache. Boletim CEPPA, Curitiba, v. 25, n. 1, p. 141-156, 2007.

TOLEDO PIZA, J. A. N. A colheita e o beneficiamento da noz macadâmia. In: REBOUÇAS, A. (Ed). Macadâmia: tecnologia de produção e comercialização. Vitória da Conquista: DFZ/UESB, 1991. p. 159-191. 